\title{
Avaliação do tempo de retenção celular e da concentração do esgoto na remoção biológica de nutrientes: remoção de nutrientes em reatores em batelada sequencial
}

A remoção biológica de nitrogênio e fósforo têm sido eficientemente alcançadas no tratamento de esgotos utilizando reatores em bateladas sequenciais (RBS). No entanto, a biodesfosfatação e desnitrificação heterotrófica ocorrem quando há carbono orgânico disponível em proporções estequiométricas, dentre outros fatores, como a idade de lodo e o tempo das fases aeróbia anaeróbia e anóxica. Neste contexto, o presente trabalho objetivou avaliar a eficiência de dois RBS na remoção biológica de nutrientes de esgoto com diferentes concentrações, sob diferentes tempos de retenção celular (TRC) e tempos de ciclo. Para isso, dois sistemas experimentais foram operados em paralelo: sistema 1 teve como afluente esgoto concentrado; e no sistema 20 afluente foi esgoto moderado. Em ambos os experimentos foram utilizados dois RBS com tempos de ciclo de 24 e 8 h e o TRC de 12 e 5 dias, respectivamente para R1 e R2. No experimento 1 foram observadas eficiências médias de remoção no R1 de $60 \%, 42 \%$ e $81 \%$, e de $83 \%, 80 \%$ e $35 \%$ no R2, respectivamente para fósforo total, ortofosfato e nitrogênio. Para o experimento 1 foram observadas eficiências médias de remoção no R1 de $60 \%, 42 \%$ e $81 \%$, e de $83 \%, 80 \%$ e $35 \%$ no R2, respectivamente para fósforo total, ortofosfato e nitrogênio. Para o experimento
2 , as eficiências médias de remoção de fósforo total, ortofosfato e nitrogênio foram respectivamente de $47 \%, 43 \%$ e $83 \%$ (R1) e $56 \%$, $54 \%$ e $33 \%$ (R2). De modo geral, a biodesfosfatação foi realizada com melhor desempenho no reator R2, quando o sistema foi operado com esgoto concentrado, enquanto os processos de nitrificação/desnitrificação foram realizados com maio eficiência no reator R1, também quando este tratava esgoto concentrado. Além disso, as relações DQO/P $(55,0$ a 65,0$)$ e DQO/N $(6,0$ a 9,0$)$ comprovaram que, em ambos os experimentos, havia matéria orgânica suficiente para que os processos de remoção de nitrogênio e fósforo ocorressem de forma adequada nos sistemas de lodos ativados.

Palavras-chave: Remoção biológica de nutrientes; Reator em batelada sequencial; Esgoto concentrado; Esgoto moderado.

\section{Assessment of cell retention time and sewage concentration in biological removal of nutrients: removal of nutrients in sequential batch reactors}

\begin{abstract}
The biological removal of nitrogen and phosphorus has been efficiently achieved in sewage treatment using sequential batch reactors (SBR). However, biophosphate and heterotrophic denitrification occur when there is organic carbon available in stoichiometric proportions, among other factors, such as the sludge age and the period time of the aerobic, anaerobic and anoxic phases. In this context, aimed to evaluate the efficiency of two SBR in biological removal of sewage nutrients with different influent concentrations, under different cell retention times (CRT) and cycle times. Therefore, two experimental systems were paralleled operated: system 1 had concentrated sewage as an influent; and in system 2 the influent was moderate sewage. In both experiments, two SBR were used with cycle times of 24 and 8 hours, and the CRT of 12 and 5 days, respectively for R1 and R2. The average removal efficiencies in experimental system (1) 11 were $60 \%, 42 \%$ and $81 \%$, and for R2 were $83 \%, 80 \%$ and $35 \%$, respectivly for total phosphorus, orthopho with higher concentrated sewage, which were operated at experimental system 1, achieved the best performance of biophosphate after R2, and the best efficiency of nitrification/denitrification process after R1. In addition, the COD/P (55 to 65) and COD/N (6 to 9) ratios proved that, in both experiments, there were enough organic matter for removal processes of nitrogen and phosphorus to occur properly in activated sludge systems.
\end{abstract}

Keywords: Biological removal of nutrients; Sequential batch reactor; Concentrated sewage; Moderate sewage.

Topic: Engenharia Ambiental

Reviewed anonymously in the process of blind peer

Kely Dayane Silva do ó (iD

Universidade Estadual da Paraíba, Brasil

http://lattes.cnpq.br/3333770979963458

http://orcid.org/0000-0001-7894-5248

kely.dayane@hotmail.com

José Tavares de Sousa (iD

Universidade Estadual da Paraíba, Brasil

http://lattes.cnpq.br/9348418607084437

http://orcid.org/0000-0002-1056-1771

tavaresuepb@gmail.com

Catarina Simone Andrade do Canto (iD) Universidade Estadual da Paraíba, Brasil http://lattes.cnpq.br/9382501092615690

http://orcid.org/0000-0002-6078-8560

csacanto@gmail.com

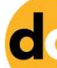

DOI: 10.6008/CBPC2179-6858.2021.006.0027
Received: 03/06/2021

Approved: 27/06/2021

\author{
Israel Nunes Henrique (iD) \\ Universidade Federal do Oeste do Pará, Brasil \\ http://lattes.cnpq.br/3418821931567495 \\ http://orcid.org/0000-0003-2127-5428 \\ israelnunes@yahoo.com.br \\ Valderi Duarte Leite (it) \\ Universidade Estadual da Paraíba, Brasil \\ http://lattes.cnpq.br/2319382787465258 \\ http://orcid.org/0000-0001-5861-7407 \\ mangabeiraleite@gmail.com \\ Wilton Silva Lopes \\ Universidade Estadual da Paraíba, Brasil \\ http://lattes.cnpq.br/1493216651945826 \\ http://orcid.org/0000-0002-0151-7664 \\ wiltonuepb@gmail.com
}

Referencing this:

Ó, K. D. S.; SOUSA, J. T.; CANTO, C. S. A.; HENRIQUE, I. N.; LEITE, V. D.; LOPES, W. S.. Avaliação do tempo de retenção celular e da concentração do esgoto na remoção biológica de nutrientes: remoção de nutrientes em reatores em batelada sequencial. Revista Ibero Americana de Ciências Ambientais, v.12, n.6, p.319-333, 2021. DOI: http://doi.org/10.6008/CBPC2179-6858.2021.006.0027 


\section{INTRODUÇÃO}

Com o aumento da população de forma desordenada nas áreas urbanas, as águas residuárias, com elevadas cargas orgânicas e de nutrientes provenientes de processos domésticos e industriais, vêm prejudicando a qualidade dos corpos receptores existentes, resultando na eutrofização de águas superficiais e na deterioração do meio ambiente.

Os esgotos domésticos, constituídos por dejetos meramente residenciais, chegam rapidamente ao ponto de alimentação dos reatores nas Estações de Tratamento de Esgoto (ETE's) com a matéria orgânica mais favorável ao processo de remoção de nutrientes, e com concentrações médias em torno de $740 \mathrm{mgO}_{2} \cdot \mathrm{L}^{-}$ 1 , sendo considerados, portanto, esgotos concentrados (SANTOS, 2019). No entanto, para certas áreas residenciais, como edifícios e áreas rurais, o descarte do esgoto muda muito em quantidade, qualidade e distribuição espacial (JORSARAEl et al., 2014; HU et al., 2020), como é o caso do esgoto sanitário que, normalmente, apresenta concentrações médias de matéria orgânica da ordem de $540 \mathrm{mgO}_{2} \cdot \mathrm{L}^{-1} \mathrm{e}$, por isso, são considerados esgotos moderados (METCALF \& EDDY, Inc., 2003). Cabe mencionar que os esgotos moderados são normalmente constituídos por esgotos domésticos e industriais, água de infiltração e a contribuição pluvial. Neste caso, o esgoto geralmente percorre um longo período até chegar ao ponto de alimentação do reator da ETE, favorecendo, por exemplo, o processo de amonificação ao longo do percurso e chegando ao ponto de alimentação mais diluído.

No Brasil, em geral, as ETE's têm sido projetadas para remover sólidos sedimentáveis e matéria orgânica carbonácea, havendo, contudo, deficiências na remoção de nutrientes. No entanto, na tentativa de reduzir as concentrações de nitrogênio e fósforo dos corpos d'água receptores, diversas tecnologias de tratamento em nível terciário vêm sendo desenvolvidas como, por exemplo, sistemas anaeróbios e aeróbios utilizando reatores operados em bateladas sequenciais - RBS (CANTO et al., 2008a; HENRIQUE et al., 2010). Neste sentido, tem-se estudado extensivamente os processos biológicos de nitrificação/desnitrificação e biodesfosfatação em sistemas de lodo ativado. O desafio em se projetar um sistema capaz de remover nitrogênio e fósforo do esgoto está na utilização da matéria orgânica carbonácea do próprio esgoto, seja ele concentrado ou moderado, como fonte de energia para o crescimento microbiano e metabolismo das bactérias desnitrificantes e organismos acumuladores de fósforo, evitando, assim, a necessidade de adição de uma fonte externa de carbono.

O processo de desnitrificação heterotrófica ocorre na presença de matéria orgânica, a qual atua como doadora de elétrons na etapa de redução do nitrogênio amoniacal a nitrito e, posteriormente, a nitrato (ROBERTSON et al., 1991). Esta etapa é geralmente conduzida por bactérias heterotróficas facultativas, que em ambiente anóxico oxidam o nitrato ou o nitrito reduzindo a matéria orgânica (VAN LOOSDRECHT et al., 1998). Além disso, durante a desnitrificação, é produzida alcalinidade e a concentração de ácido carbônico é reduzida. Desta forma, a desnitrificação reverte parcialmente os efeitos da nitrificação e, portanto, eleva o pH do meio (METCALF \& EDDY, Inc., 2003).

Na remoção de fósforo, o processo anaeróbio é dimensionado para a ocorrência apenas da digestão 
Avaliação do tempo de retenção celular e da concentração do esgoto na remoção biológica de nutrientes: remoção de nutrientes em reatores em batelada sequencial

Ó, K. D. S.; SOUSA, J. T.; CANTO, C. S. A.; HENRIQUE, I. N.; LEITE, V. D.; LOPES, W. S.

parcial da matéria orgânica, ou seja, até a produção de ácidos voláteis, que são utilizados pelos organismos acumuladores de fósforo (PAO) na formação de poli-hidroxi-alcanoatos (PHA). É nesta etapa que há liberação de fósforo para o meio líquido. Quando os PAO ingressam em zonas anóxicas ou aeradas, utilizam os PHA já no interior das células para evitar a competição com os organismos heterotróficos ordinários pelo substrato. Desta forma, ocorre grande incorporação de fósforo pelos organismos heterotróficos ordinários e, em seguida, descarte de lodo em excesso efetivando, assim, a remoção de fósforo do sistema (STENSEL, 1991; SURAMPALLI et al., 1997; BUNCE et al., 2018).

Normalmente, para a efetivação do processo de remoção, utiliza-se a matéria orgânica naturalmente presente no meio. Contudo, dependo do tipo de processo e das condições operacionais, há a necessidade de se adicionar uma fonte extra de carbono. O carbono adicional é normalmente derivado de compostos orgânicos solúveis, como acetato, glicose ou propionato. Contudo, o seu custo pode restringir sua aplicação prática (CHU et al., 2011). Assim, utilizar como fonte de matéria orgânica o próprio esgoto para remoção de nutrientes é uma alternativa viável. O esgoto concentrado é constituído por uma grande quantidade de matéria orgânico e pela presença de ácidos graxos voláteis de cadeia curta, que atuam como doadores de elétrons e determinam a eficácia do processo de remoção de nutrientes (MANDEL et al., 2019). Portanto, fatores que afetam ambos os processos são as razões $\mathrm{C} / \mathrm{N}$ e $\mathrm{C} / \mathrm{P}$, o que pode variar em função das características do processo e da matéria orgânica (BROUGHTON et al., 2008; CANTO et al., 2008b; ZHOU et al., 2010).

Outros parâmetros que também podem influenciar o processo simultâneo de remoção de nutrientes são o tempo de ciclo do processo e o tempo de retenção celular (METCALF \& EDDY, Inc., 2003). A idade do lodo pode influenciar sobremaneira o processo, pois tem ligação direta com o crescimento dos microrganismos responsáveis por cada processo. Diante do exposto, o presente trabalho teve por objetivo avaliar o desempenho de dois reatores operados em bateladas sequenciais, operados com diferentes tempos de retenção celular e tempos de ciclo, quanto à eficiência de remoção biológica de nutrientes de esgotos concentrados e moderados.

\section{METODOLOGIA}

Os sistemas experimentais foram instalados e monitorados na Estação Experimental de Tratamento Biológico de Esgotos Sanitários (EXTRABES), localizada no município de Campina Grande (PB). Os experimentos foram realizados em reatores operados em bateladas sequenciais (RBS), os quais foram alimentados com esgoto concentrado e moderado, como descrito a seguir.

\section{Esgotos Concentrado e Moderado}

O esgoto concentrado utilizado foi proveniente de um conjunto habitacional vertical, localizado nas proximidades da EXTRABES. O esgoto era bombeado através de um conjunto motorbomba (modelo ANAUGER 700 5G, com potência de 450 watts,) para um tanque de equalização $\left(1 \mathrm{~m}^{3}\right)$, localizado próximo ao 
Avaliação do tempo de retenção celular e da concentração do esgoto na remoção biológica de nutrientes: remoção de nutrientes em reatores em batelada sequencial

Ó, K. D. S.; SOUSA, J. T.; CANTO, C. S. A.; HENRIQUE, I. N.; LEITE, V. D.; LOPES, W. S.

sistema experimental. A partir do tanque de equalização, o esgoto era encaminhado por meio de uma bomba sapo (modelo monofásica 700 5G, marca ANAUGER) até o reator.

O esgoto moderado utilizado foi proveniente da rede coletora de esgotos da cidade (Companhia de Água e Esgoto da Paraíba - CAGEPA). Como no caso anterior, o esgoto era bombeado para um tanque de equalização $\left(1 \mathrm{~m}^{3}\right)$ e, a partir deste tanque, para o sistema experimental por meio de uma bomba sapo (modelo ANAUGER 700 5G, com potência de 450 watts).

\section{Sistemas Experimentais}

Os reatores foram operados em regime de bateladas sequencias, variando-se o tempo de retenção celular, o tempo de ciclo e o tipo de esgoto com o objetivo principal de verificar o efeito destes parâmetros sobre o processo de remoção de nitrogênio e fósforo.

Os ensaios foram conduzidos como mostrado na Tabela 1. Os reatores R1 e R2 foram alimentados com esgoto concentrado (EC) e moderado (EM), variando-se os tempos de ciclo e retenção celular. No experimento 1, o sistema foi alimentado com esgoto concentrado e tempos de ciclo de $24 \mathrm{~h}$ e $8 \mathrm{~h}$ para os reatores R1 e R2, respectivamente. Por outro lado, os tempos de retenção celular (TRC) foram, respectivamente, 12 dias e 5 dias. No experimento 2 foram utilizados os mesmos tempos de retenção celular e de ciclo, porém, o sistema foi operado tratando esgoto moderado.

Tabela 1: Procedimento Experimental.

\begin{tabular}{lll}
\cline { 2 - 3 } & Reatores & R2 \\
\hline Experimento 1 & R1 & Concentrado \\
Tipo de esgoto & & 8 \\
Tempo de ciclo (horas) & Concentrado & 5 \\
Tempo de retenção celular (dias) & 24 & Moderado \\
\hline Experimento 2 & 12 & 8 \\
Tipo de esgoto & & Moderado \\
Tempo de ciclo (horas) & 24 & 5 \\
Tempo de retenção celular (dias) & 12 & \\
\hline
\end{tabular}

\section{Procedimento Experimental}

O procedimento experimental foi dividido em duas etapas: experimento 1 e experimento 2 (Tabela 1). Em cada experimento, os reatores R1 e R2 (Figura 1) foram operados em paralelo, tratando esgoto concentrado por um período de 120 dias e esgoto moderado por um período de 80 dias.
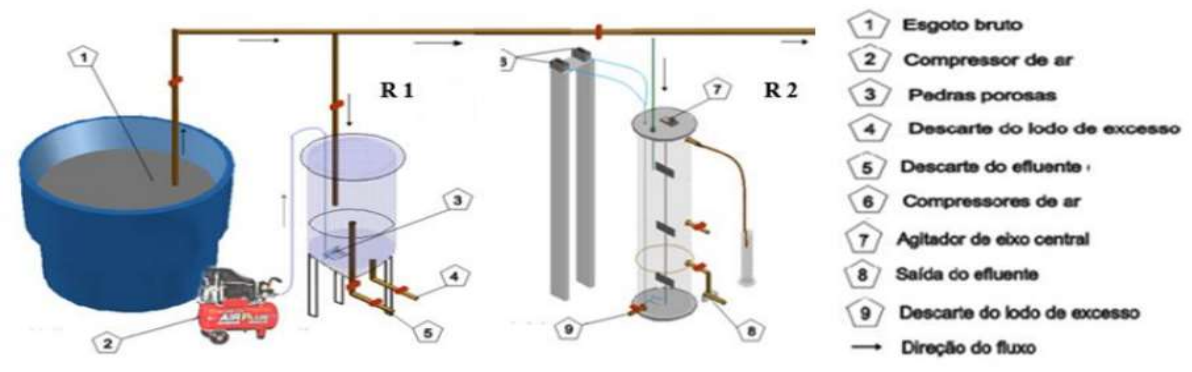

Figura 1: Sistema experimental: reatores R1 e R2. 
Avaliação do tempo de retenção celular e da concentração do esgoto na remoção biológica de nutrientes: remoção de nutrientes em reatores em batelada sequencial

\section{Experimento 1}

No experimento 1 (Figura 1), os reatores R1 e R2 foram projetados para tratar 60 L/ciclo de esgoto concentrado utilizando diferentes TRC's e tempos de ciclo (Tabela 1). O reator R1 foi confeccionado em fibra de vidro, possuindo $145 \mathrm{~cm}$ de diâmetro, $100 \mathrm{~cm}$ de comprimento e $60 \mathrm{~L}$ de volume útil, sendo $25 \mathrm{~L}$ destinados à sedimentação da biomassa ativa ao final do ciclo. O TRC foi de 12 dias. O reator R2, que foi operado com três ciclos diários (tratando 20 L/ciclo), foi confeccionado em acrílico, possuindo $50 \mathrm{~cm}$ de diâmetro, $95 \mathrm{~cm}$ de comprimento e $28 \mathrm{~L}$ de volume útil, sendo $8 \mathrm{~L}$ utilizados para a sedimentação da biomassa. O TRC foi mantido em 5 dias.

Para que os processos de nitrificação/desnitrificação e biodesfosfatação ocorressem, foi necessária a introdução de períodos com e sem aeração ao longo de cada ciclo. Assim, cada ciclo operacional foi dividido da seguinte forma:

Reator R1: tempo de ciclo de 24h (1 ciclo/dia) - Alimentação: no início do ciclo, durante 10 min; Fase sem aeração: durante 120 min logo após a alimentação, e mais 6 períodos de 60 min intercalados com os períodos com aeração; Fase com aeração: durante 170 min iniciados imediatamente após o primeiro período com aeração, e mais 6 períodos de 120 min intercalados com os períodos sem aeração; Decantação: iniciada ao final da última fase com aeração e com duração de 50 min, e Descarte: realizado durante os 10 min finais do ciclo.

Reator R2: tempo de ciclo de 8h (3 ciclos/dia) - Alimentação: 14 L durante 5 min ao início do ciclo, e mais $14 \mathrm{~L}$ durante 5 min ao final do primeiro período com aeração; Fase sem aeração: iniciada logo após cada alimentação e com duração de 1h; Fase com aeração: iniciada logo após cada fase sem aeração e com duração de 150 min; Decantação: iniciada ao final da segunda fase com aeração e com duração de 45 min, e Descarte: realizado durante os 5 min finais do ciclo. As Figuras 2 e 3 resumem o exposto.

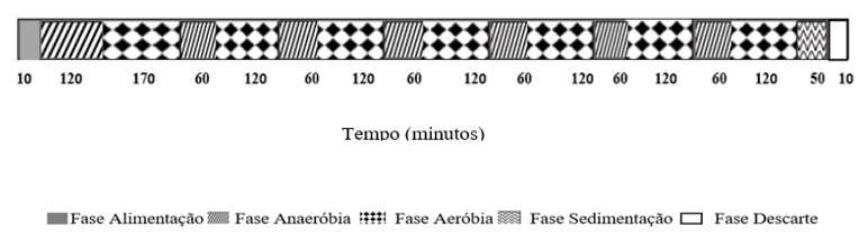

Figura 2: Distribuição das fases de operação do RBS ao longo de um ciclo - Reator R1.

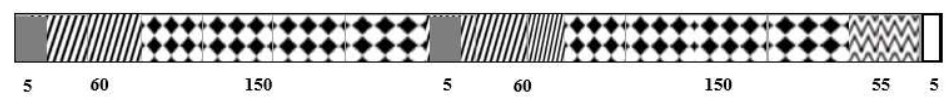

Tempo (minutos)

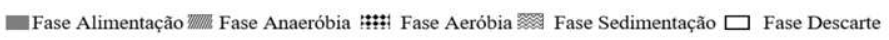

Figura 3: Distribuição das fases de operação do RBS ao longo de um ciclo - Reator R2.

Com o objetivo de promover a suspensão do lodo no licor misto, foi utilizado um agitador mecânico constituído por 6 pás equidistantes e submetido a uma baixa velocidade de rotação ( $45 \mathrm{rpm}$ ). Ademais, para promover a aeração do sistema, foi utilizado um dispositivo contendo pedras porosas ( 6 unidades) e ligado 
Avaliação do tempo de retenção celular e da concentração do esgoto na remoção biológica de nutrientes: remoção de nutrientes em reatores em batelada sequencial

Ó, K. D. S.; SOUSA, J. T.; CANTO, C. S. A.; HENRIQUE, I. N.; LEITE, V. D.; LOPES, W. S.

a um compressor (Air Plus MSI 8,5/25, com 2 HP de potência e volume do reservatório de ar de 25L), o qual foi alocado na base do reator com o objetivo de distribuir de forma homogênea o ar injetado no sistema (Figura 1). Vale mencionar que todo o sistema foi controlado por timers digitais, os quais foram responsáveis pelo acionamento das bombas de carga e descarga, do compressor e do agitador mecânico.

\section{Experimento 2}

O experimento 2 foi conduzido da mesma forma que o experimento 1, porém tratando esgoto moderado.

\section{Métodos Analíticos}

Os métodos analíticos utilizados para a quantificação de pH, concentração de matéria orgânica (DQO

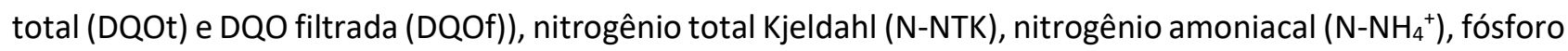
total $\left(P_{t}\right)$, ortofosfato $\left({\mathrm{P}-\mathrm{PO}_{4}}^{-3}\right)$ e sólidos e suas frações foram definidos segundo APHA et al. (2012). Alcalinidade total e ácidos graxos voláleis (AGV) foram quantificados utilizando-se metodologia determinada por Buchauer et al. (1998). Nitrito $\left(\mathrm{N}^{-\mathrm{NO}_{2}}{ }^{-}\right)$e nitrato $\left(\mathrm{N}^{-\mathrm{NO}_{3}}{ }^{-}\right)$foram quantificados por Cromatografia de Íons, utilizando-se o Ion Chromatography System Dionex ICS-1100 da Thermo Scientific e acessórios (coluna Dionex $^{\mathrm{TM}}$ IonPac ${ }^{\mathrm{TM}}$ AS23, pré-coluna Dionex ${ }^{\mathrm{TM}}$ IonPac $^{\mathrm{TM}}$ AG23, célula de condutividade DS6, supressora ASRS $2 \mathrm{~mm}$ ), e tendo como eluente uma solução 4,5 $\mathrm{mM} \mathrm{Na}_{2} \mathrm{CO}_{3} / 0,8 \mathrm{mM} \mathrm{NaHCO}$.

As amostras dos esgotos concentrado e moderado (afluentes) e dos efluentes tratados eram coletadas 1 vez por semana, e, posteriormente, analisadas. Cabe mencionar que as análises foram feitas em duplicata e os valores médios obtidos para cada parâmetro foram posteriormente discutidos.

\section{RESULTADOS E DISCUSSÃO}

Na Tabela 2 são apresentados os valores médios dos parâmetros monitorados durante o desenvolvimento dos experimentos 1 e 2, e, nas Figuras 4 a 6, os perfis de concentração ao longo do período.

Tabela 2: Características físico-químicas dos afluentes (EC e EM) e dos efluentes dos reatores R1 e R2 para os diferentes tempos de retenção celular avaliados.

\begin{tabular}{|c|c|c|c|c|c|c|c|c|c|c|}
\hline \multicolumn{6}{|c|}{ Esgoto Concentrado (EC) } & \multicolumn{5}{|c|}{ Esgoto Moderado (EM) } \\
\hline $\begin{array}{l}\text { Parâmetros } \\
\left({\left.\mathrm{mg} . \mathrm{L}^{-1}\right)}\right.\end{array}$ & $\begin{array}{l}\text { AF } \\
\bar{x} \pm \delta\end{array}$ & $\begin{array}{l}\mathrm{R} 1 \\
\overline{\mathrm{x}} \pm \delta\end{array}$ & $\begin{array}{l}\text { EF } \\
\%\end{array}$ & $\begin{array}{l}\mathrm{R2} \\
\overline{\mathrm{x}} \pm \delta\end{array}$ & $\begin{array}{l}\text { EF } \\
\%\end{array}$ & $\begin{array}{l}\text { AF } \\
\bar{x} \pm \delta\end{array}$ & $\begin{array}{l}\mathrm{R} 1 \\
\overline{\mathrm{x}} \pm \delta\end{array}$ & $\begin{array}{l}\text { EF } \\
\%\end{array}$ & $\begin{array}{l}\mathrm{R} 2 \\
\overline{\mathrm{x}} \pm \delta\end{array}$ & $\begin{array}{l}\text { EF } \\
\%\end{array}$ \\
\hline DQOt & $907 \pm 9,7$ & $86 \pm 5,75$ & 91 & $92 \pm 4$ & 90 & $464 \pm 12,7$ & $19,4 \pm 2,2$ & 96 & $22,6 \pm 1,9$ & 95 \\
\hline DQOf & $396 \pm 7$ & $55,7 \pm 6$ & 86 & $70,5 \pm 6,5$ & 82 & $178,5 \pm 6,7$ & $13,8 \pm 2$ & 92 & $16,7 \pm 1,4$ & 90 \\
\hline AGV* & $286,4 \pm 11$ & $26,8 \pm 10,3$ & - & $41,7 \pm 14,5$ & - & $120,4 \pm 8,4$ & $6,1 \pm 1,9$ & - & $18 \pm 6$ & - \\
\hline $\mathrm{AT}^{* *}$ & $534 \pm 15,3$ & $410 \pm 6,8$ & - & $510 \pm 7,9$ & - & $502 \pm 10,5$ & $348 \pm 13,2$ & - & $411 \pm 3,9$ & - \\
\hline N-NTK & $105 \pm 1,2$ & $19 \pm 0,8$ & 82 & $79 \pm 1,3$ & 24 & $74,5 \pm 1$ & $12 \pm 2$ & 84 & $50 \pm 0,9$ & 33 \\
\hline $\mathrm{N}-\mathrm{NH}_{4}^{+}$ & $73 \pm 7,3$ & $14 \pm 0,9$ & - & $76,2 \pm 7,5$ & - & $47 \pm 3$ & $6 \pm 2$ & - & $34,4 \pm 0,4$ & - \\
\hline $\mathrm{N}-\mathrm{NO}_{2}^{-}$ & ND & $1 \pm 0,2$ & - & ND & - & ND & ND & - & ND & - \\
\hline $\mathrm{N}-\mathrm{NO}_{3}^{-}$ & ND & $7,4 \pm 0,8$ & - & $0,50 \pm 0,3$ & - & ND & $7 \pm 0,6$ & - & $0,22 \pm 0,2$ & - \\
\hline Pt & $15,2 \pm 0,1$ & $6 \pm 0,8$ & 60 & $2,6 \pm 0,5$ & 83 & $9,6 \pm 0,2$ & $5,1 \pm 0,8$ & 47 & $4,2 \pm 0,1$ & 56 \\
\hline $\mathrm{P}_{-} \mathrm{PO}_{4}{ }^{3-}$ & $9,2 \pm 0,2$ & $5,3 \pm 0,5$ & 42 & $1,8 \pm 0,3$ & 80 & $7 \pm 0,1$ & $4 \pm 0,1$ & 43 & $3,2 \pm 0,1$ & 54 \\
\hline
\end{tabular}

Legenda: AF: afluente; EF\%: eficiência de remoção; R1: efluente tratado em TRC de 12 dias; R2: efluente tratado em TRC de 5 dias TRC: tempo de retenção celular; ${ }^{*}$ em mgHAc. $L^{-1}$; ${ }^{* *}$ em $\mathrm{mgCaCO}_{3} . \mathrm{L}^{-1}$; ND: não detectado. Obs.: Para o EC, média de 10 resultados obtidos durante o período de equilíbrio dinâmico, ou seja, após 60 dias de experimento. Para o EM, média de 10 resultados obtidos durante o período de equilíbrio dinâmico, ou seja, após 20 dias de experimento. 


\section{Desempenho dos reatores $\mathbf{R} 1$ e $\mathbf{R} 2$ na remoção de material carbonáceo}

Os reatores utilizados no experimento 1 , durante o período de 120 dias, apresentaram boa remoção de material carbonáceo após 60 dias de operação, período em que o reator entrou em equilíbrio dinâmico com eficiências médias de remoção de DQO total e filtrada de 91 e $86 \%$ no R1, e de 90 e 82\% no R2, respectivamente. 0 experimento 2, que teve duração de 80 dias, também apresentou boa eficiência de remoção de material carbonáceo, entrando em equilíbrio dinâmico após 20 dias de operação. Neste caso, a eficiências médias de remoção de DQO total e filtrada no R1 foram 96 e 92\% e, no R2, de 95 e $90 \%$, respectivamente (Tabela 2 ).

Na Figura 4 são apresentados os perfis das concentrações de DQO total (4a) e filtrada (4b) dos EC e EM, com concentrações afluentes médias após o período de equilíbrio dinâmico de $907 \mathrm{mgO}_{2} \cdot \mathrm{L}^{-1}$ e 396 $\mathrm{mgO}_{2} \cdot \mathrm{L}^{-1}$, no reator $\mathrm{R} 1$, e $464 \mathrm{mgO}_{2} \cdot \mathrm{L}^{-1}$ e $178,5 \mathrm{mgO}_{2} \cdot \mathrm{L}^{-1}$, no reator $\mathrm{R} 2$, respectivamente (Tabela 2). Segundo METCALF \& EDDY, Inc., (2003), estas concentrações são consideradas como sendo médias e elevadas (médias até $430 \mathrm{mgO}_{2} \cdot \mathrm{L}^{-1}$ e elevadas acima $\left.800 \mathrm{mgO}_{2} \cdot \mathrm{L}^{-1}\right)$, o que pode garantir matéria orgânica em proporções estequiométricas para que o processo de remoção de nutrientes se dê de forma efetiva nas condições de operação propostas. Resultados semelhantes foram obtidos por Costa et al. (2013), Chen et al. (2015) e Fernandes et al. (2016) em estudos utilizando reatores RBS, o que demonstra a efetividade do reator no tratamento terciário de esgotos concentrados e moderados.

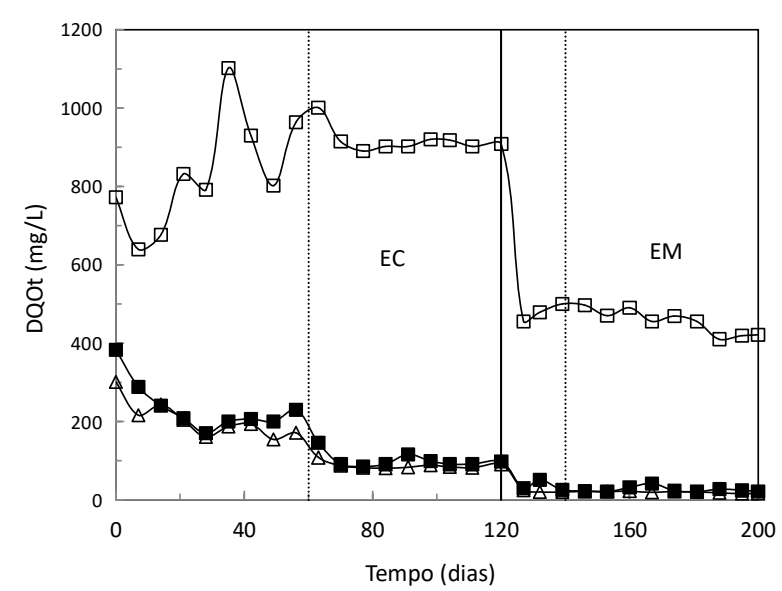

(a)

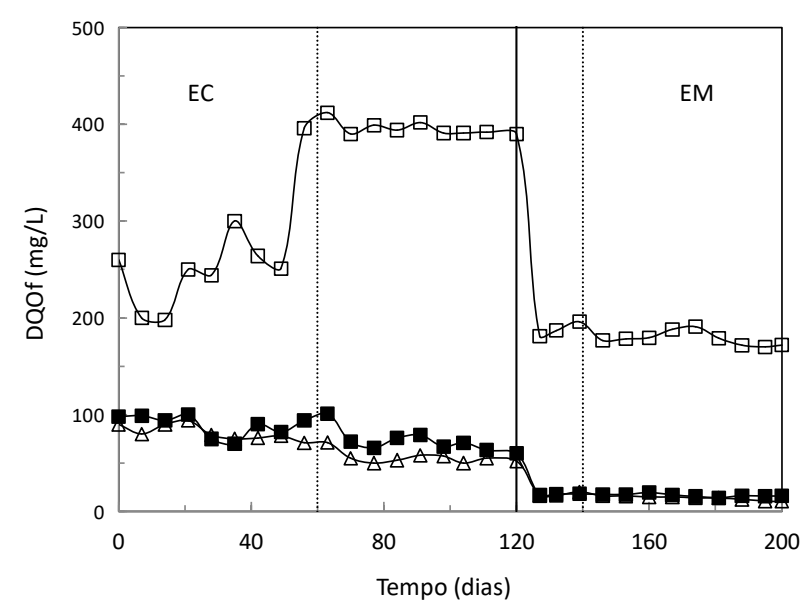

(b)

Figura 4: Perfis de concentração de DQOt e DQOf obtidos durante o período de monitoramento. Legenda: $\square$ afluente; $\Delta$ - efluente R1; I - efluente R2; linha sólida - divisão entre esgoto concentrado e esgoto moderado; linhas pontilhadas - início do período de equilíbrio dinâmico de cada experimento.

Observando-se as Figuras 4a e 4b, verifica-se que após o período de equilíbrio dinâmico ter sido atingido houve uma estabilização da DQO afluente, o que pode ser decorrente da presença da caixa de equalização localizada entre o reator e o ponto de coleta. A caixa de estabilização possivelmente permitiu a pré-estabilização da matéria orgânica afluente, mantendo as concentrações aproximadamente constantes. Para o esgoto concentrado, a DQO total variou de $900 \mathrm{mgO}_{2} \cdot \mathrm{L}^{-1}$ a $1000 \mathrm{mgO}_{2} \cdot \mathrm{L}^{-1}$, enquanto para o esgoto moderado, variou de $85 \mathrm{mgO}_{2} \cdot \mathrm{L}^{-1}$ a $115 \mathrm{mgO}_{2} \cdot \mathrm{L}^{-1}$.

Os efluentes dos reatores R1 e R2 do EM, apresentaram menores concentrações de DQO total e 
filtrada do que os efluentes dos reatores R1 e R2 do EC. Provavelmente, está maior eficiência de remoção de matéria orgânica foi devido ao menor tempo de adaptação das bactérias presentes no sistema, visto que só foram necessários 20 dias de operação para que os reatores entrassem em equilíbrio dinâmico. Resultados semelhantes foram obtidos por Liu et al. (2013), que utilizaram um sistema composto por 3 reatores (anaeróbio, aeróbio e anóxico) dispostos em sequência e operando com ciclos de 8 horas. Neste caso, a eficiência de remoção de matéria orgânica foi da ordem de $90 \%$.

Outros autores (YUAN et al., 2016; BUENO et al., 2019), realizando estudos semelhantes, também atestaram que foi possível manter a biomassa em suspensão e em concentração suficiente para a realização da degradação dos compostos orgânicos, indicando uma boa estabilidade do sistema quanto à remoção de matéria orgânica e, sobretudo, quando esgoto com características de esgoto moderado foi tratado.

\section{Alcalinidade e pH}

Os sistemas estudados não apresentaram variações de $\mathrm{pH}$ e alcalinidade que pudessem comprometer ou influenciar de forma expressiva os processos de tratamento avaliados. Além disso, os parâmetros mantiveram-se adequados para os processos metabólicos durante todo o período operacional (Figuras $5 \mathrm{a}$ e $5 \mathrm{~b}$ ). Os valores de $\mathrm{pH}$ no afluente e efluente dos reatores RBS estiveram próximos da neutralidade e, portanto, favoráveis à existência de maior diversidade biológica por estarem na faixa de pH considerada ideal (entre 6 e 9), proporcionando, assim, condições favoráveis ao tratamento biológico (METCALF \& EDDY, Inc., 2003).

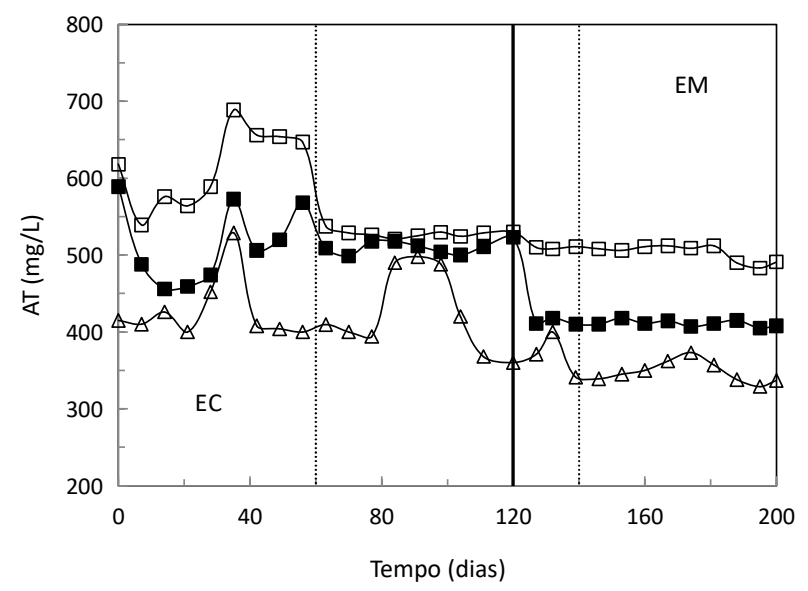

(a)

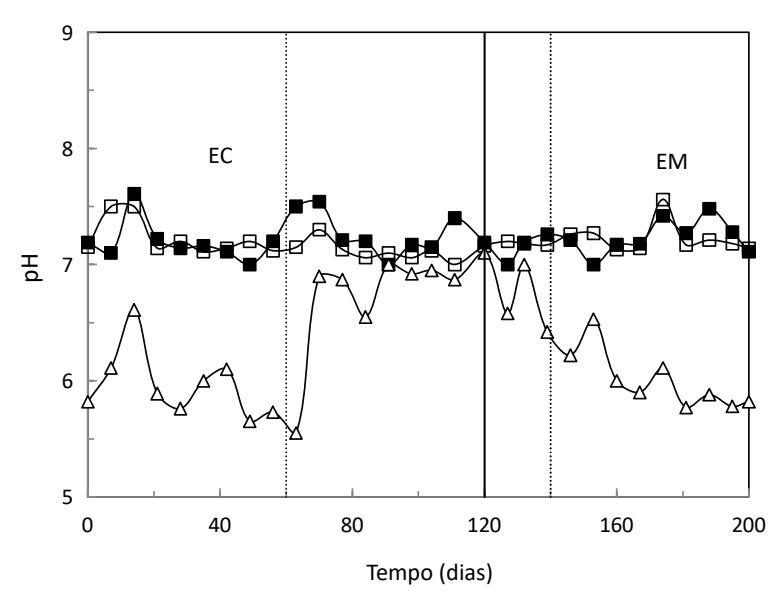

(b)

Figura 5: Perfis de concentração de alcalinidade e $\mathrm{pH}$ obtidos durante o período de monitoramento. Legenda: $\square$ afluente; $\Delta$ - efluente R1; $\boldsymbol{~ - ~ e f l u e n t e ~ R 2 ; ~ l i n h a ~ s o ́ l i d a ~ - ~ d i v i s a ̃ o ~ e n t r e ~ e s g o t o ~ c o n c e n t r a d o ~ e ~ e s g o t o ~ m o d e r a d o ; ~ l i n h a s ~}$ pontilhadas - início do período de equilíbrio dinâmico de cada experimento.

Foi possível observar que o pH sofreu uma leve acidificação no reator R1, apresentando valores entre 6,35 a 6,56 (Figura 5b). Porém, estes valores ainda estão em conformidade com o padrão de lançamento estabelecidos pela Resolução CONAMA n 430/2011, a qual estipula a faixa de pH entre 5 a 9 (BRASIL, 2011). Vale frisar, contudo, que tal acidificação pode estar diretamente relacionada ao processo de nitrificação (Tabela 2), o qual pode alterar o pH do meio após à liberação de prótons, ao consumo natural de alcalinidade 
Avaliação do tempo de retenção celular e da concentração do esgoto na remoção biológica de nutrientes: remoção de nutrientes em reatores em batelada sequencial

e, consequentemente, à redução da capacidade de tamponamento do meio (METCALF \& EDDY, Inc., 2003; ANTILEO et al., 2013).

\section{Desempenho dos reatores $\mathbf{R} 1$ e $\mathbf{R} 2$ na remoção de nutrientes}

Conforme mostra a Tabela 2, as concentrações médias de N-NTK nos efluentes dos reatores R1 e R2, após o período de equilíbrio dinâmico, foram de 19,0 mgN-NTK.L-1 e 79,0 mgN-NTK.L-1 e 12,0 mgN-NTK.L-1 e 50,0 mgN-NTK. $\mathrm{L}^{-1}$, respectivamente para os esgotos concentrado e moderado. Quanto ao nitrogênio amoniacal $\left(\mathrm{N}_{-} \mathrm{NH}_{4}{ }^{+}\right)$, os valores médios foram $14,0 \mathrm{mgN}-\mathrm{NH}_{4} \cdot \mathrm{L}^{-1}$ e $76,0 \mathrm{mgN}-\mathrm{NH}_{4} \cdot \mathrm{L}^{-1}$ para os reatores R1 e R2 tratando $\mathrm{EC}$, e $6,0 \mathrm{mgN}-\mathrm{NH}_{4} \cdot \mathrm{L}^{-1}$ e $34,0 \mathrm{mgN}-\mathrm{NH}_{4} \cdot \mathrm{L}^{-1}$ para os reatores $\mathrm{R} 1$ e $\mathrm{R} 2$ tratando $\mathrm{EM}$, respectivamente.

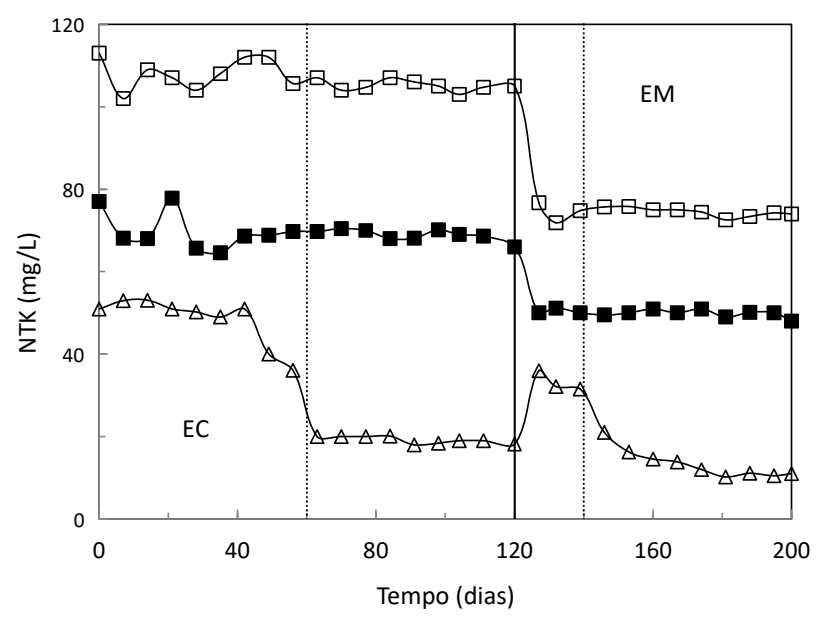

(a)

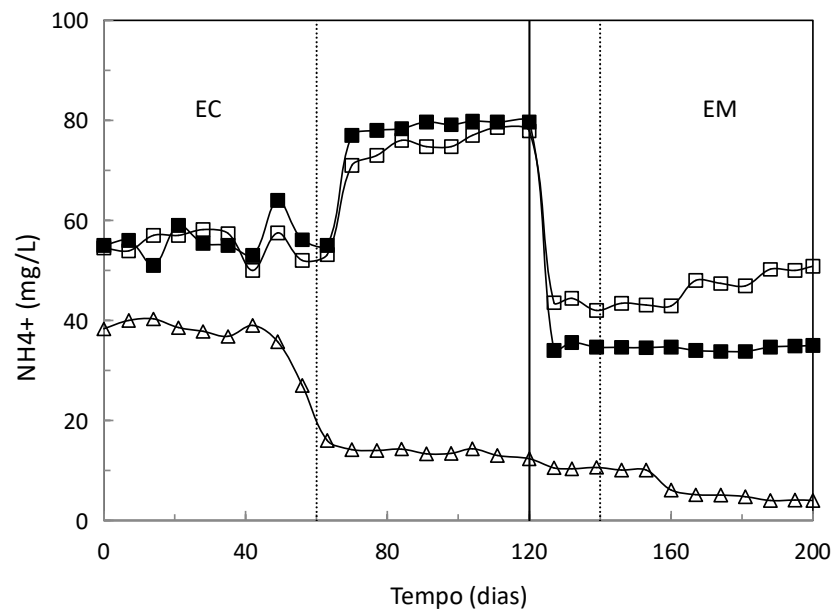

(b) 2

Figura 6: Perfis de concentração de NTK e $\mathrm{NH}_{4}{ }^{+}$obtidos durante o período de monitoramento. Legenda: $\square$ - afluente; $\Delta$ - efluente R1; - - efluente R2; linha sólida - divisão entre esgoto concentrado e esgoto moderado; linhas pontilhadas início do período de equilíbrio dinâmico de cada experimento.

As Figuras $6 a$ e $6 \mathrm{~b}$ apresentam os perfis de concentração de N-NTK e N-NH${ }_{4}{ }^{+}$relativos aos esgotos ensaiados e aos seus respectivos efluentes tratados. Observa-se que os resultados apresentaram concentrações de N-NTK em torno de 20,0 mgN-NTK.L ${ }^{-1}$ após o período de equilíbrio dinâmico dos reatores, quando o EM foi tratado. Neste caso, as concentrações de nitrogênio amoniacal mantiveram-se em valores abaixo de 6,0 mgN-NH m. $^{-1}$ após o equilíbrio dinâmico ter sido atingido. Contudo, quando o reator R2 foi utilizado, a mesma efetividade não foi observada e a eficiência de remoção diminuiu consideravelmente (Tabela 2), principalmente quando o esgoto concentrado foi tratado. Estes resultados propõem que a remoção de nitrogênio por nitrificação e desnitrificação foi mais acentuada no experimento 2 , associada ao TRC de 12 dias.

Quanto às concentrações médias de nitrito e nitrato no reator R1 para o efluente do EC, foram obtidos valores de $1,0 \mathrm{mgN}-\mathrm{NO}_{2}{ }^{-} \cdot \mathrm{L}^{-1}$ e $7,4 \mathrm{mgN}-\mathrm{NO}_{3}{ }^{-} \cdot \mathrm{L}^{-1}$, respectivamente, após 60 dias de operação do sistema. Estes valores condizem com os reportados em estudos realizados por Bueno et al. (2019), com concentrações de nitrato no efluente variando de 6,5 a 7,7, mg N-NO${ }_{3}^{-}$. L-1. Daniel et al. (2009) também utilizaram reatores operados em bateladas sequenciais com fluxo intermitente e conseguiram uma remoção de mais de $90 \%$ de nitrogênio através do processo simultâneo de nitrificação e desnitrificação, com 
concentração de oxigênio dissolvido de $2,0-2,7 \mathrm{mg} \mathrm{O} \cdot \mathrm{O}^{-1}$.

Quando o EM foi tratado no reator R1, o nitrito também foi rapidamente convertido em nitrato, indicando que o processo de nitrificação ocorreu de forma efetiva (83\%). Concentrações médias de nitrato de 7,0 mgN-NO $\mathrm{N}_{3} \cdot \mathrm{L}^{-1}$ foram observadas após o período de equilíbrio dinâmico. Neste período também foram observadas eficiência de nitrificação de $81 \%$.

De acordo com as médias dos resultados de eficiência na remoção de nitrogênio (Tabela2), pode-se perceber que o objetivo de promover a nitrificação e desnitrificação no reator R1, tratando tanto EC quanto EM, foi alcançado, pois foi perceptível a ocorrência deste processo com a conversão de nitrogênio amoniacal a nitrito e nitrato, além da ocorrência do consumo da matéria orgânica no meio reacional. Entretanto, salienta-se que não houve desnitrificação completa no reator R1 tratando EC, uma vez que ainda pôde ser verificada a presença de nitrito e nitrato no efluente deste reator. Isto ocorreu, possivelmente, devido à atividade dos organismos desnitrificantes acumuladores de fósforo (ODAF), que atuaram no sistema e competiram por matéria orgânica solúvel. Quando o reator R1 tratando EC atingiu o equilíbrio dinâmico, ocorreu 60\% de eficiência de remoção de fósforo total, como verificado na Figura 7(a) e na Tabela 2.

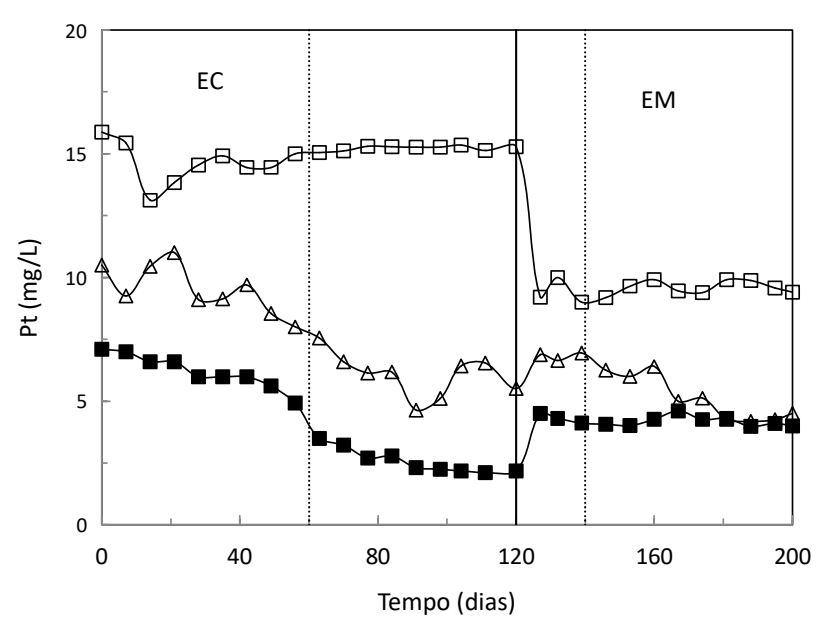

(a)

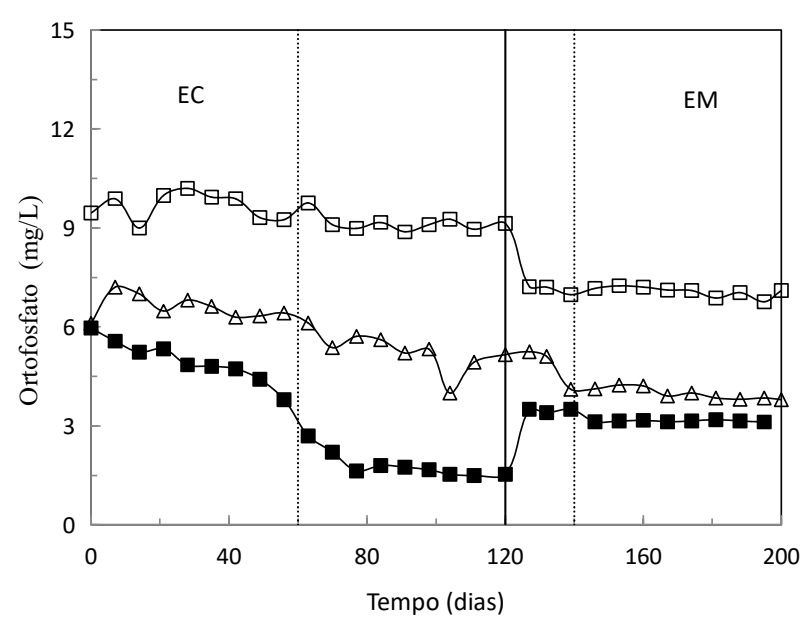

(b)

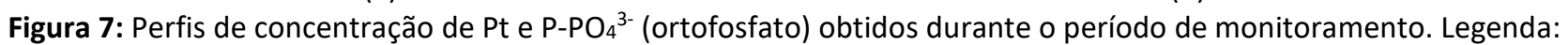
$\square$ - afluente; $\Delta$ - efluente R1; - efluente R2; linha sólida - divisão entre esgoto concentrado e esgoto moderado; linhas pontilhadas - início do período de equilíbrio dinâmico de cada experimento.

Em consonância com os resultados das concentrações de matéria orgânica em termos de consumo de DQO solúvel pelos organismos consumidores de fósforo, as Figuras $7(a)$ e $7(b)$ apresentam os perfis de concentração de fósforo total com valores inferiores a $3 \mathrm{mgPt} . \mathrm{L}^{-1}$ no período de estabilização. Neste caso, a eficiência média de remoção de fósforo foi de $83 \%$ no reator R2, tratando EC. Com relação às concentrações de ortofosfato, estas foram menores que $2 \mathrm{mgP}-\mathrm{PO}_{4}{ }^{3-} \cdot \mathrm{L}^{-1}$, com eficiência média de remoção de $80 \%$ no reator R1, também tratando EC.

Para o esgoto moderado tratado no reator R2, apesar da concentração de matéria orgânica ter apresentado pequenas variações, as eficiências de remoção de fósforo total e ortofosfato foram de 56 e $54 \%$, respectivamente. No entanto, a remoção de fósforo foi superior no EC tratado, possivelmente devido à baixa concentração de DQO solúvel do EM, um dos fatores que limita os processos biológicos de uma eficiente 
Avaliação do tempo de retenção celular e da concentração do esgoto na remoção biológica de nutrientes: remoção de nutrientes em reatores em batelada sequencial

remoção de fósforo (HU et al., 2014).

Dentre os diversos fatores e parâmetros que podem interferir no processo de remoção biológica de fósforo, tem-se as concentrações dos compostos nitrogenados. Uma pequena quantidade de nitrato no início da fase anaeróbia provoca o acúmulo de fósforo pelos ODAP em detrimento aos organismos acumuladores de fósforo durante a fase aeróbia (OEHMEN et al., 2007). Todavia, os ODAP podem utilizar o nitrato como receptor de elétrons em concentrações superiores a $5 \mathrm{mg} \cdot \mathrm{L}^{-1}$, prejudicando a biodesfosfatação (OEHMEN et al., 2007). No entanto, verificou-se, no presente trabalho, que os tratamentos no reator $R 2$, tratando tanto $E C$ quanto $E M$, não foram prejudicados pela presença de nitrato, o qual esteve presente sempre em concentrações inferiores a $1 \mathrm{mgN}-\mathrm{NO}_{3} \cdot \mathrm{L}^{-1}$ (Tabela2).

Por outro lado, no reator R1, tanto tratando EC quanto EM, a eficiência média de remoção de fósforo foi inferior àquela observada no reator R2. Este fato pode ser devido à limitação de matéria orgânica rapidamente biodegradável, pois o processo de remoção de fósforo, especificamente a etapa de liberação de fósforo no ambiente anaeróbio e de remoção de nitrogênio na etapa de desnitrificação, competem por carbono orgânico. Além disso, e a eficiência de remoção de fósforo está ligada à relação estequiométrica entre o carbono e os nutrientes (N e P) presentes no afluente a ser tratado (GUO et al., 2011). No reator R1, tratando tanto EC quanto EM, ocorreu a remoção de nitrogênio com maior eficiência do que a remoção de fósforo.

Para melhor visualização do comportamento dos parâmetros de qualidade dos efluentes quanto à remoção de fósforo, são apresentados na Tabela 3 os valores médios de DQO total e filtrada, SST, SSV, fósforo total e ortofosfato do lodo de excesso, obtidos após o período de equilíbrio dinâmico dos reatores R1 e R2 tratando EC.

Pode-se observar na Tabela 3 que os valores das concentrações médias dos lodos têm características diferentes, como maiores concentrações de matéria orgânica total e filtrada e de sólidos, assim como maior concentração média de fósforo incorporada ao lodo do reator R2, caracterizando-se com maior remoção de fósforo em relação ao reator R1.

Tabela 3: Características do lodo de excesso dos reatores R1 e R2 tratando EC.

\begin{tabular}{lll}
\hline Parâmetros & Lodo R1 & Lodo R2 \\
(mg. $\left.\mathbf{L}^{-1}\right)$ & $\overline{\mathrm{x}} \pm \delta$ & $\overline{\mathrm{x}} \pm \delta$ \\
\hline DQOt & $7254 \pm 260$ & $10391 \pm 232$ \\
DQOf & $201 \pm 57$ & $222 \pm 75$ \\
SST & $6382 \pm 94$ & $12180 \pm 206$ \\
SSV & $4904 \pm 21$ & $6251 \pm 116$ \\
$\mathrm{Pt}$ & $60.9 \pm 21$ & $303 \pm 63$ \\
$\mathrm{P}_{-\mathrm{PO}_{4}{ }^{3-}}$ & $29,7 \pm 8$ & $171 \pm 12$ \\
\hline
\end{tabular}

A concentração de sólidos suspensos voláteis (SSV) no reator R2 manteve-se em média em 6251 mgSSV. $\mathrm{L}^{-1}$, enquanto no reator R1 o valor médio foi de $4904 \mathrm{mgSSV} . \mathrm{L}^{-1}$. Teoricamente, quanto mais alta a concentração de sólidos em suspensão do licor misto no tanque de aeração, maior é a eficiência do processo, favorecendo a remoção de maiores concentrações de nutrientes devido à maior concentração de SSV. Segundo van Haandel et al. (1999), devido à maior fração de material inorgânico na forma de polifosfato 
Avaliação do tempo de retenção celular e da concentração do esgoto na remoção biológica de nutrientes: remoção de nutrientes em reatores em batelada sequencial

Ó, K. D. S.; SOUSA, J. T.; CANTO, C. S. A.; HENRIQUE, I. N.; LEITE, V. D.; LOPES, W. S.

presente nos organismos acumuladores de fósforo, a fração SSV/SST com valor de referência de 0,46 é bem menor nestes organismos do que nos organismos heterotróficos, onde este valor se mantém em torno de 0,8 . Contudo, quando se analisam os lodos dos reatores R1 e R2, percebe-se um aumento significativo na concentração das frações de SSV no reator R2 com a razão de SSV/SST de 0,51 mgSSV.(mgSST)-1 (valor de referência igual 0,46$)$. No reator $\mathrm{R} 1$, a relação foi de $0,76 \mathrm{mgSSV}(\mathrm{mgSST})^{-1}$, caracterizando-se como organismos heterotróficos não acumuladores de fósforo.

\section{Relações DQO/NTK e DQO/Pt}

A Figura 8 apresenta as relações normalizadas DQOt/NTK e DQOt/Pt relativas aos EC e EM (afluente e efluente, tratados com TRC de 12 e 5 dias. Contudo, os valores médios da razão DQOt/NTK para os esgotos concentrado e moderado, obtidos durante o período de monitoramento, variaram entre 6 e 9, enquanto a razão DQOt/Pt variaram entre 55 e 65. Estes resultados atestam que havia matéria orgânica suficiente para que os processos de remoção de nitrogênio e fósforo ocorressem de forma adequada nos sistemas utilizados.

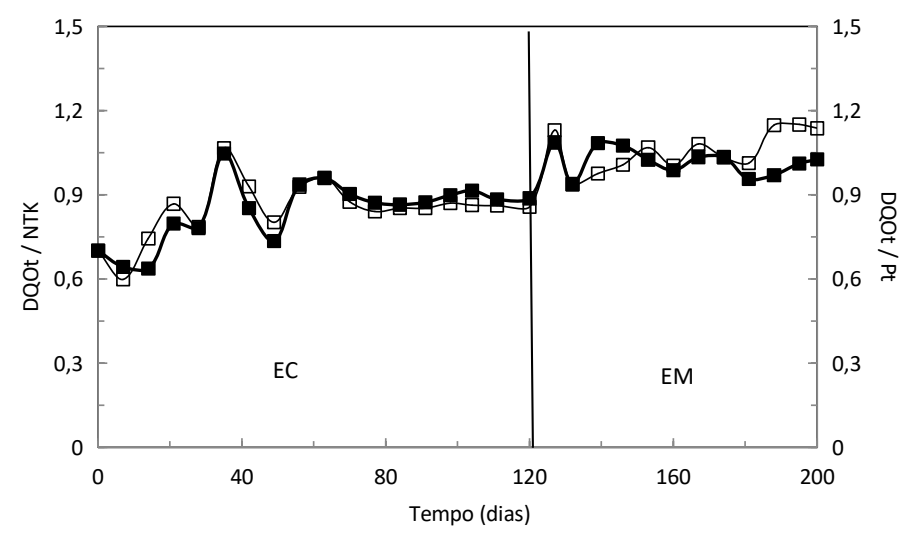

Afluente

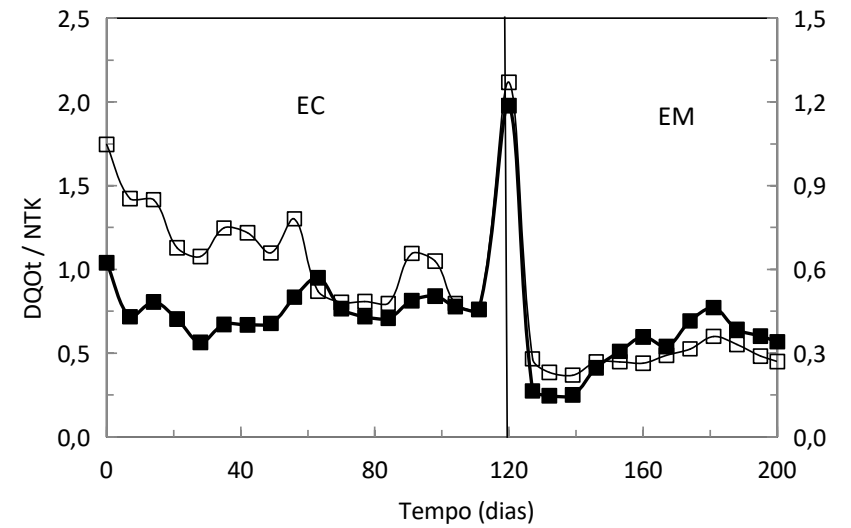

Reator R1

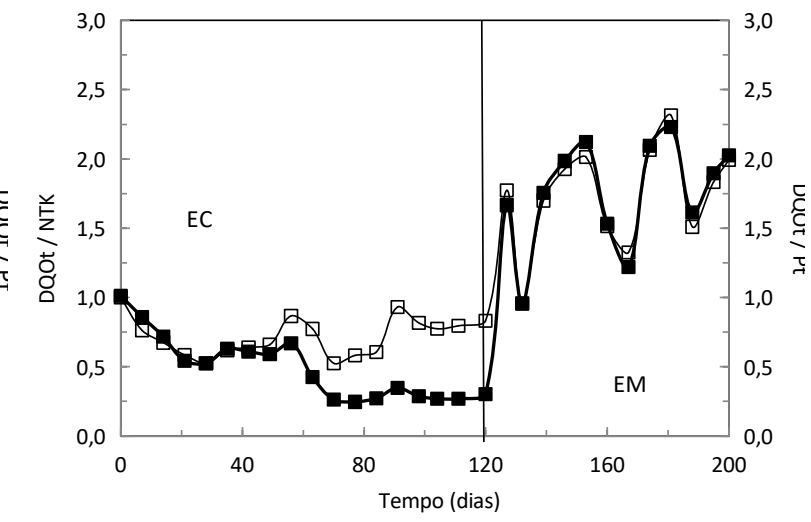

Reator R2

Figura 8: Relações normalizadas DQO/NTK e DQO/P em função do tempo de monitoramento. Legenda: $\square$ - DQO/Pt; - DQO/N-NTK; linha sólida - divisão entre esgoto concentrado e esgoto moderado.

Em pesquisa realizada por Guo et al. (2011), utilizando-se um sistema em bateladas sequenciais e alternando condições anaeróbias e aeróbias com concentração de OD variando entre 0,1 e 0,6 mg/L, a eficiência de remoção de fósforo total aumentou de 40\% (DQO/N igual a 1,5; DQO/P igual a 8,9 e fosfato efluente igual a $9 \mathrm{mg} / \mathrm{L}$ ) para $73 \%$ (DQO/N igual a 2,6; DQO/P igual a 15 e fosfato efluente igual a $4 \mathrm{mg} / \mathrm{L}$ ) e 
Avaliação do tempo de retenção celular e da concentração do esgoto na remoção biológica de nutrientes: remoção de nutrientes em reatores em batelada sequencial

Ó, K. D. S.; SOUSA, J. T.; CANTO, C. S. A.; HENRIQUE, I. N.; LEITE, V. D.; LOPES, W. S.

95\% (DQO/N de 4,1; DQO/P de 24 e fosfato efluente de $1 \mathrm{mg} / \mathrm{L}$ ), após o reator atingir o equilíbrio dinâmico. Resultados similares são apresentados por Jaafari et al. (2017). De acordo com os resultados obtidos, a eficiência de remoção de fósforo aumentou significativamente com a estabilização da carga orgânica e com o tempo de operação.

Quanto aos processos de remoção biológica de nitrogênio, a relação DQO/N interfere diretamente na eficiência do processo, buscando-se uma relação ótima para que o processo de nitrificação/desnitrificação ocorra de forma satisfatória. Contudo, muitos esgotos apresentam valores inferiores aos da relação ótima apontada na literatura (próximos a 9), o que resulta em uma remoção limitada de nitrogênio total. No presente trabalho, o EC apresentou relação próxima a 9,0. No entanto, o EM apresentou relação DQO/N de 6,13, e quando foi operado com TRC de 12 dias, não interferiu no processo de remoção biológica de nitrogênio de forma significativa.

\section{CONCLUSÕES}

Com base no trabalho realizado, conclui-se que: - Quanto à eficiência de remoção biológica de nitrogênio via nitrificação e desnitrificação, o R1 alcançou o melhor desempenho no experimento 2, tratando esgoto moderado. - Comparando-se os tratamentos 1 e 2, o reator R2 operado em bateladas sequenciais com TRC de 5 dias, atingiu maior eficiência de remoção biológica de fósforo tratando esgoto concentrado, com eficiências de remoção de fósforo total e ortofosfato de 83 e $80 \%$, respectivamente. Influenciada pela maior concentração de DQO solúvel e confirmada pela maior relação de DQO/P de 61,2, também foi possível observar maior quantidade de SSV presente no lodo do R2. Estas características favoreceram maior remoção de fósforo, confirmada pela relação de SSV/SST de 0,51 mgSSV.(mgSST)-1.

A remoção de nitrogênio foi mais evidenciada no reator R1, tratando esgoto moderado, e influenciada pela idade de lodo. No entanto, a matéria orgânica disponível parece não ter sido suficiente para que os processos de remoção de nitrogênio e biodesfosfatação ocorressem concomitantemente e de maneira eficiente. Além disso, os efluentes do R1 que tratava afluente de esgoto moderado e do R1 que tratava afluente concentrado mantiveram-se com médias de $7,0 \mathrm{mg} \cdot \mathrm{L}^{-1}$ e $7,4 \mathrm{mg} . \mathrm{L}^{-1}$ de nitrato, respectivamente. Estas concentrações estão dentro da faixa de lançamento em corpos d'água e com concentrações de nitrogênio amoniacal nos efluentes menores que $16 \mathrm{mg} \mathrm{N}-\mathrm{NH}_{4}{ }^{+} \mathrm{L}^{-1}$, produzindo, portanto, efluente para lançamento em corpo d'água conforme a Resolução CONAMA 430/2011.

\section{REFERÊNCIAS}

ANTILEO, C.; MEDINA, H.; BORNHARDT, C.; MUÑOZ, C.; JARAMILLO, F.; PROAL, J.. Actuators monitoring system for real-time control of nitrification-denitrification via nitrite on long-term operation. Chemical Engineering Journal, v.223, p.467-478, 2013. DOI:

https://doi.org/10.1016/i.cej.2013.02.079

APHA; AWWA; WEF. American Public Health Association; American Water Works Association; World Economic Forum. Standard methods for the examination of water and wastewater. 22 ed. Washington: APHA, 2012.

BRASIL. Resolução CONAMA n. 430, de 13 e maio de 2011. Dispõe sobre as condições e padrões de lançamento de efluentes, complementa e altera a Resolução no 357, de 17 de março de 2005, do Conselho Nacional do Meio Ambiente - CONAMA. Brasília: CONAMA, 2011.

BROUGHTON, A.; PRATT, S.; SHILTON, A.. Enhanced biological phosphorus removal for high-strength wastewater 
Avaliação do tempo de retenção celular e da concentração do esgoto na remoção biológica de nutrientes: remoção de nutrientes em reatores em batelada sequencial

with a low rbCOD:P ratio. Bioresource Technology, v.99, n.5, p.1236-1241, 2008. DOI:

https://doi.org/10.1016/j.biortech.2007.02.013

BUCHAUER, K. A. A.. Comparison of two simple titration procedure to determine volatile fatty acids in effluents to wastewater and sludge treatment process. Water S. A., v.24, n.1, p.49-56, 1998.

BUENO, R. F.; CAMPOS, F.; RIVERA, M. M.; LENIS, C.; PIVELI, R. P.. Remoção simultânea de material orgânico, nitrogênio e fósforo em um reator em bateladas sequenciais com biofilme de leito móvel operado pelo processo anaeróbioanóxico-óxico. Engenharia Sanitária e Ambiental, v.24, n.4, p.747-760, 2019. DOI: https://doi.org/10.1590/s141341522019125711

BUNCE, J. T.; NDAM, E.; OFITERU, D.; MOORE, A.; GRAHAM, W. D.. A review of phosphorus removal technologies and their applicability to small-scale domestic wastewater treatment systems. Frontiers in Environmental Science, v.6, n.8, p.1-15, 2018. DOI:

https://doi.org/10.3389/fenvs.2018.00008

CANTO, C. S. A.; RATUSZNEI, S. M.; RODRIGUES, J. A. D.; ZAIAT, M.; FORESTI, E.. Effect of ammonia load on efficiency of nitrogen removal in an SBBR with liquid-phase circulation. Brazilian Journal of Chemical Engineering, v.25, n.2, p.275289, 2008b. DOI: http://doi.org/10.1590/S010466322008000200007

CANTO, C. S. A.; RODRIGUES, J. A. D.; RATUSZNEI, S. M.; ZAIAT, M.; FORESTI, E.. Feasibility of

nitrification/denitrification in a sequencing batch biofilm reactor with liquid circulation applied to post-treatment. Bioresource Technology, v.99, n.3, p.644-654. 2008a. DOI: https://doi.org/10.1016/j.biortech.2006.12.040

CHEN, Q.; NI, J.; MA, T.; LIU, T.; ZHENG, M.. Bioaugmentation treatment of municipal wastewater with heterotrophic aerobic nitrogen removal bacteria in a pilot-scale SBR. Bioresource Technology, v.183, p.25-32, 2015. DOI: https://doi.org/10.1016/i.biortech.2015.02.022

CHU, L.; WANG, J.. Nitrogen removal using biodegradable polymers as carbon source and biofilm carriers in a moving bed biofilm reactor. Chemical Engineering Journal, v.170, n.1, p.220-225, 2011. DOI:

http://doi:10.1016/j.cej.2011.03.058

COSTA, R. H. R.; WOLFF, D. B.; SOUTO, V. S.. Performance and kinectics aspects of nitrogen removal in a biofilm sequencing batch reactor. International Journal of Environmental Research, v.7, n.2, p.513-522, 2013. DOI: https://doi.org/10.22059/IJER.2013.631

DANIEL, L. M. C.; POZZI, E.; FORESTI, E.; CHINALIA, F. A. Removal of ammonium via simultaneous nitrificationdenitrification nitrite shortcut in a single packed-bed batch reactor. Bioresource Technology, v.100, n.3, p.1100-1107, 2009. DOI: https://doi.org/10.1016/j.biortech.2008.08.003

FERNANDES, H.; ANTONIO, R. V.; COSTA, R. H. R..

Investigation of full-scale step-fed SBR under low dissolved oxygen: performance and microbial community response.

Water Quality Research Journal of Canada, v.51, n.2, p.141-
152, 2016. DOI: https://doi.org/10.2166/warjc.2016.042

GUO, H.; ZHOU, J.; ZHANG, S.; GUO, Z.. Characteristics of nitrogen and phosphorus removal in a sequencing batch reactor. Journal of Environmental Science, v.23, p.S110S113, 2011. DOI: https://doi.org/10.1109/ICEET.2009.521

HENRIQUE, I. N.; SOUSA, J. T.; CEBALLOS, B. S. O.; BRASIL, D. P.. Remoção biológica de fósforo em reatores em bateladas sequenciais com diferentes tempos de retenção de sólidos. Engenharia Sanitária e Ambiental, v.15 n.2, p.197-204, 2010. DOI: https://doi.org/10.1590/S1413$\underline{41522010000200012}$

HU, X.; XIE, L.; SHIM, H.; ZHANG, S.; YANG, D.. Biological nutrient removal in a full-scale anoxic/anaerobic/aerobic/pre-anoxic-MBR plant for low $\mathrm{C} / \mathrm{N}$ ratio municipal wastewater treatment. Chinese Journal of Chemistry Engineering, v.22, n.4, p.447-454, 2014. DOI: https://doi.org/10.1016/S1004-9541(14)60064-1

HU, Z.; LI, D.; LIU, Y.; ZHANG, C.; GUAN, D.; YAO, H.. Performance of chemical catalytic biofilm technology for decentralized sewage treatment. Environmental Engineering Science, v.37, n.11, p.757-768, 2020. DOI: https://doi.org/10.1089/ees.2019.0510

JAAFARI, J.; SEYEDSALEHI, M.; SAFARI, G.H.; ARJESTAN, M E.; BARZANOUNI, H.; GHADIMI, S.; HARATIPOUR, P.. Simultaneous biological organic matter and nutrient removal in an anaerobic/anoxic/oxic (A2O) moving bed biofilm reactor (MBBR) integrated system. International Journal of Environmental Science and Technology, v.14, n.2, p.291304, 2017. DOI: https://doi.org/10.1007/s13762-016-1206-x

JORSARAEI, A.; GOUGOL, M.; VAN LIER, J. B.. A cost effective method for decentralized sewage treatment. Process Safety and Environmental Protection, v.92, n.6, p.815-821, 2014. DOI: https://doi.org/10.1016/j.psep.2013.04.001

LIU, G.; XU, X. Y.; ZHU, L.; XING, S.; CHEN, J. Y.. Biological nutrient removal Ina continuous anaerobic-aerobic-anoxic process treating synthetic domestic wastewater. Chemical Engineering Journal, v.225, p.223-229, 2013. DOI: https://doi.org/10.1016/j.cej.2013.01.098

MANDEL, A.; ZEKKER, L.; JAAGURA, M.; TENNO, T.. Enhancement of anoxic phosphorus uptake of denitrifying phosphorus removal process by biomass adaption. International Journal of Environmental Science and Technology. 2019. DOI: https://doi.org/10.1007/s13762018-02194-2

METCALF \& EDDY, Inc. Wastewater engineering: treatment and reuse. 4 ed. New York: McGraw-Hill, 2003.

OEHMEN, A.; LEMOS, P. C.; CARVALHO, G.; YUAN, Z.; KELLER, J.; BLACKALL, L. L.; REIS, M. A.. Advances in enhanced biological phosphorus removal: From micro to macro scale. Water Research, v.41, p.2271-2300, 2007. DOI: https://doi.org/10.1016/j.watres.2007.02.030

ROBERTSON, L. A.; KUENEN, J. G.. Combined heterotrophic nitrification in Thiosphaera pantothopha and other bacteria. Antonie van Leeuwenhoek, v.57, p.139-152, 1990. DOI: https://doi.org/10.1099/00221287-134-4-857 
Avaliação do tempo de retenção celular e da concentração do esgoto na remoção biológica de nutrientes: remoção de nutrientes em reatores em batelada sequencial

SANTOS, B. A.. Caracterização, tratamento e gerenciamento de subprodutos de correntes de esgotos segregadas e não segregadas em empreendimentos habitacionais. Fortaleza, 2019.

STENSEL, H. D.. Principles of Biological Phosphorus Removal. In: SEDLAK, R.. Phosphorus and nitrogen removal from municipal wastewater: principles and practice. 2 ed. 1991. p.141-166.

SURAMPALLI, R. Y.; TYAGI, D.; SCHEIBLE, O. K.; HEIDMAN, J. A.. Nitrification, denitrification and phosphorus removal in sequential batch eactors. Bioresource Technology, v.61, n.2, p.151-157, 1997. DOI: https://doi.org/10.1016/S09608524(97)00034-5

VAN HAANDEL, A. C.; MARAIS, G. O.. Comportamento do sistema de lodo ativado. Campina Grande: EPGRAF, 1999.
VAN LOOSDRECHT, M. C. M.; JETTEN, M. S. M.

Microbiological Conversions in Nitrogen Removal. Water Science and Technology, v.38, n.1, p.1-7, 1998. DOI: https://doi.org/10.1016/S0273-1223(98)00383-7

YUAN, Y.; LIU, J.; MA, B.; LIU, Y.; WANG, B.; PENG, Y.. Improving municipal wastewater nitrogen and phosphorous removal by feeding sludge fermentation products to sequencing batch reactor (SBR). Bioresource Technology, v.222, p.326-334, 2016. DOI:

https://doi.org/10.1016/i.biortech.2016.09.103

ZHOU, S.; ZHANG, X.; FENG, L.. Effect of different types of electron acceptors on the anoxic phosphorus uptake activity of denitrifying phosphorus-removing bacteria. Bioresource Technology, v.101, p.1603-1610, 2010. DOI: https://doi.org/10.1016/j.biortech.2009.09.032

A CBPC - Companhia Brasileira de Produção Científica (CNPJ: 11.221.422/0001-03) detém os direitos materiais desta publicação. Os direitos referem-se à publicação do trabalho em qualquer parte do mundo, incluindo os direitos às renovações, expansões e disseminações da contribuição, bem como outros direitos subsidiários. Todos os trabalhos publicados eletronicamente poderão posteriormente ser publicados em coletâneas impressas sob coordenação da Sustenere Publishing, da Companhia Brasileira de Produção Científica e seus parceiros autorizados. Os (as) autores (as) preservam os direitos autorais, mas não têm permissão para a publicação da contribuição em outro meio, impresso ou digital, em português ou em tradução. 